\title{
Prolonged eradication of urogenital mycoplasmas after administration of tetracycline to men in the Antarctic
}

\author{
A. D. MACLEOD, * P. M. FURR, AND D. TAYLOR-ROBINSON \\ The British Antarctic Survey and the M.R.C. Clinical Research Centre, Harrow, Middlesex
}

\begin{abstract}
Summary
Meatal swabs were obtained at intervals over I year from 23 men in the Antarctic. A 5-day course of tetracycline was given to twelve of them. In retrospect it was found that the antibiotic had been received by two men who were harbouring ureaplasmas, one of whom also had $M$. hominis. After treatment, these organisms were not found in any of the swabs taken over the next year, except in a swab from one of the men following sexual contact after this time. One of the twelve men developed N.S.U. just before arriving in the Antarctic. He responded clinically to a shorter course of tetracycline and ureaplasmas were not recovered from a meatal swab immediately thereafter. However, without further sexual contact, ureaplasmas and disease recurred about a month later. This time, after a 5-day course of tetracycline, disease was not seen, and ureaplasmas were not isolated, over the next year. In contrast, ureaplasmas were isolated consistently over a year from two men who were not given the antibiotic. The evidence strongly suggests that, under natural conditions, the most likely cause of mycoplasmas, particularly ureaplasmas, recurring in the genital tract after apparently adequate tetracycline therapy, is re-infection as a result of sexual re-exposure.
\end{abstract}

\section{Introduction}

In a previous study (Holmes, Furr, and TaylorRobinson, 1974), mycoplasmas were isolated from the urogenital tract of men in the Antarctic, some of whom had been there for as long as 31 months. Most men had chronic infections and it was clear that

Received for publication March 26, 1976

Address for reprints: Dr. D. Taylor-Robinson, Clinical Research Centre, Watford Road, Harrow, Middlesex HA1 3UJ

^Present address: M.R.C. Common Cold Unit, Coombe Road, Salisbury, Wilts. re-infection as a result of sexual contact was not a factor in the persistence of organisms. Indeed, a characteristic of mycoplasmal infections in man, animals, and tissue cultures is the tendency for them to become chronic. In mycoplasmal infections, antibiotic therapy often fails to eliminate the organisms. This is seen in mycoplasma-contaminated tissue cultures (Stanbridge, 1971) and it is well known that Mycoplasma pneumoniae may persist in the respiratory tract of infected persons (Smith, Chanock, Friedewald, and Alford, 1967) and hamsters (Slotkin, Clyde, and Denny, 1967) long after they have received tetracycline in doses known to inhibit the growth of the organisms in vitro. The occurrence of mycoplasmas in the genital tract after apparently adequate tetracycline therapy may be due to reinfection as a result of re-exposure or to the multiplication of a strain which has been inhibited but not killed by the antibiotic. In normal clinical practice it is usually impossible to decide between these alternatives, but an opportunity to investigate this problem arose from a further study of the exclusively male populations of British Antarctic Survey stations. Samples were taken for mycoplasma testing from most of the men at two stations and some of them were given tetracycline and sampled before and repeatedly after administration of the antibiotic.

\section{Material and methods}

Subjects

Two groups of wintering men were studied over the period December, 1973, to April, 1975, part of this time being in transit on board the Survey's ships. The men were situated at Adelaide Island, which lies close to the Grahamland peninsula of Antarctica, and at Signy Island, some 800 miles north east in the South Orkneys. The trial was explained fully to everyone and all who participated were volunteers. Thirteen men were studied at Adelaide Island and ten at Signy Island, and of these, nine had already spent the previous year in Antarctic isolation. The last ports of call of the ships where sexual contacts could be made were Montevideo, Uruguay; Mar-del-Plata, Argentina; and Port Stanley in the Falkland Islands. 
Diagnosis of urethritis

Two men developed a urethral discharge after leaving Montevideo. Some of the discharge, mixed with saline, was observed microscopically and a smear was Gramstained. The finding of Gram-negative intracellular diplococci was taken as diagnostic of gonorrhoea. The diagnosis of non-specific urethritis (NSU) was based on the occurrence of leucocytes but the failure to find diplococci. It was not possible to culture for gonococci. The two-glass urine test was used to assist in diagnosing urethritis and to assess the recovery from disease.

Tetracycline administration

A course of tetracycline ('Steclin', Squibb) was given to twelve of 23 men. This consisted of one $250 \mathrm{mg}$ tablet taken post-prandially four times a day for 5 days. Use of tetracyclines during the period of the study was restricted to the trial. Subjects with a history of any form of atopy were excluded from the tetracycline group.

\section{Collection of specimens and storage}

This was supervised by A.D.M. at Adelaide Island and by an assistant at Signy Island with radio co-ordination. Meatal swabs were collected immediately before antibiotic administration and afterwards at 4 to 12-week intervals, over a period of 12 months from May, 1974, to April, 1975. In addition, specimens were taken from some men 3 to 4 months before the trial and from two men about 6 months after they had returned to England. In all, at least six swab specimens were obtained from each man. These were taken before the first micturition of the day or, when this was not possible, at least 1 hour after urination. Each individual, after careful instruction, swabbed himself by inserting and rotating a plain cotton-wool swab (Exogen Ltd.) about $1 \mathrm{~cm}$ into the meatus; this swab was snapped off into $1.5 \mathrm{ml}$ of glucose-containing mycoplasma medium (Manchee and Taylor-Robinson, 1968). On the Antarctic bases and aboard ship specimens were stored at $-40^{\circ} \mathrm{C}$. Specimens collected from some men about 4 months before tetracycline administration were twice partially thawed because of refrigerator failures lasting 12 to $36 \mathrm{hrs}$ and 24 to $48 \mathrm{hrs}$, respectively. On each occasion the temperature rose to $-3^{\circ}$ to $-2^{\circ} \mathrm{C}$. Specimens were returned by sea to England where they were stored at $-70^{\circ} \mathrm{C}$.

Mycoplasma isolation and tetracycline sensitivity test

The laboratory workers were unaware which subjects had received tetracycline. Mycoplasmas were isolated as described previously (Holmes and others, 1974). The number of organisms is expressed as colour-changing units (c.c.u.) per $0.2 \mathrm{ml}$. Organisms which metabolized arginine were identified as $M$. hominis by the disc inhibition technique using specific antiserum. The in vitro sensitivity of ureaplasmas to tetracycline was tested by a micro-technique (Taylor-Robinson, 1967) in which each well of the micro-plate contained about $10^{4}$ c.c.u. of the organisms. The dilution of antibiotic at which there was complete inhibition of colour change was initially recorded after incubation at $36^{\circ} \mathrm{C}$ for $18 \mathrm{hrs}$, and finally after 5 days.

\section{Results}

Mycoplasma isolation before and after tetracycline administration

Ureaplasmas were isolated from the specimens taken from four of 22 men immediately before the course of tetracycline and $M$. hominis was also isolated from one of these four men. Tetracycline was given to two of the four men who harboured ureaplasmas, including the man infected by $M$. hominis. After the course of antibiotic, ureaplasmas and $M$. hominis were not isolated from any of the specimens taken over a period of about 12 months, whereas the two men who had not received antibiotic continued to shed ureaplasmas during this time (Table). Men who were apparently free from ureaplasmas initially, and who did not receive tetracycline, continued to have negative specimens throughout the period of observation. About 6 months after returning to England, a meatal specimen was obtained from each of two men who previously had mycoplasma-negative specimens after receiving tetracycline. The specimen from one of the men, who had had sexual contact, contained $10^{5}$ c.c.u. of ureaplasma organisms but he had not experienced any symptoms or signs of urethritis.

TABLE Occurrence of genital ureaplasmas in men, some of whom were given tetracycline

\begin{tabular}{|c|c|c|c|c|c|c|}
\hline \multicolumn{2}{|c|}{ Date on which } & \multicolumn{5}{|c|}{$\begin{array}{l}\text { Number of ureaplasmas (c.c.u. } / 0 \cdot 2 \mathrm{ml} \text { ) } \\
\text { in specimens from subjects }\end{array}$} \\
\hline \multirow[t]{2}{*}{$\begin{array}{l}\text { Swab } \\
\text { taken }\end{array}$} & \multirow[t]{2}{*}{$\begin{array}{l}\text { Tetracycline } \\
\text { given }\end{array}$} & \multicolumn{2}{|c|}{$\begin{array}{l}\text { Not given } \\
\text { tetracycline }\end{array}$} & \multicolumn{3}{|c|}{$\begin{array}{l}\text { Given } \\
\text { tetracycline }\end{array}$} \\
\hline & & $A$ & $\boldsymbol{B}$ & $C$ & $D$ & $E$ \\
\hline $\begin{array}{l}26.12 .73 \\
30.12 .73\end{array}$ & $26.12 .73^{a}$ & & & & & $10^{4}$ \\
\hline $\begin{array}{r}21.1 .74 \\
27.1 .74 \\
1.2 .74\end{array}$ & $27.1 .74^{b}$ & $10^{3}$ & & $10^{3}$ & $10^{3}\left(10^{2}\right)^{d}$ & $\begin{array}{l}10^{4} \\
10^{3} \\
\end{array}$ \\
\hline $\begin{array}{l}1.2 .74 \\
2.5 .74 \\
7.5 .74\end{array}$ & $2.5 .74^{\mathrm{c}}$ & $\begin{array}{l}10^{2} \\
10^{4}\end{array}$ & $\begin{array}{l}10^{4} \\
10^{4}\end{array}$ & $\frac{10^{2}}{-}$ & $\begin{array}{l}10^{3}\left(10^{2}\right) \\
-(-)\end{array}$ & $\bar{z}$ \\
\hline 8.6.74 & & $10^{3}$ & $10^{4}$ & - & - (-) & - \\
\hline 15.8 .74 & & $10^{4}$ & $10^{4}$ & - & $-(-)$ & - \\
\hline 9.11 .74 & & $10^{3}$ & & - & $-(-)$ & - \\
\hline $\begin{array}{l}12.2 .75 \\
10.4 .75\end{array}$ & & $10^{4}$ & $10^{6}$ & 二 & $-(-)$ & - \\
\hline $8.12 .75^{\mathrm{e}}$ & & & & $10^{5}$ & & \\
\hline
\end{tabular}

3-day course to $\mathrm{E}$ only

D5-day course to $E$ only

c5-day course to $C$ and $D$ only

dTitre of $M$. hominis in parenthesis

-About 6 months after returning to England and after sexual contact

Effect of refrigerator failure on ureaplasma isolation

Specimens which had been partially thawed and refrozen on two occasions were available from four men whose subsequent specimens, not subjected to this treatment, contained mycoplasmas. The thawed specimen from each man contained a similar number of organisms to the specimens which remained frozen until the time of testing.

\section{Occurrence of urethritis}

One man developed gonorrhoea after leaving Montevideo on the way to the Antarctic, but mycoplasmas were not isolated from him before treatment. Another man E (Table), who was the twenty-third man in the 
study, developed N.S.U. and a meatal specimen obtained from him immediately before treatment contained $10^{4}$ c.c.u. of ureaplasma organisms. He received tetracycline $250 \mathrm{mg}$. four times a day for 3 days, after which the discharge and ureaplasmas disappeared. However, a meatal swab taken 24 days after the completion of treatment was found to contain $10^{4}$ c.c.u. of ureaplasmas. One week after this, without further sexual exposure, the discharge recurred and a further meatal swab confirmed the presence of ureaplasmas. This time the patient was treated with a 5-day course of tetracycline and the discharge, symptoms, and ureaplasmas disappeared and did not recur over the 12-month observation period.

\section{Tetracycline-sensitivity of mycoplasmas}

Eight ureaplasma isolates from the four men who harboured them and from the man who suffered relapsing N.S.U., in addition to the $M$. hominis isolate, were tested. Growth of all the isolates was inhibited initially by $0.005 \mu \mathrm{g} . / \mathrm{ml}$. tetracycline. Continued incubation resulted in mycoplasma growth at this concentration of tetracycline, but none of the isolates multiplied at a concentration of $0.5 \mu \mathrm{g} . / \mathrm{ml}$.

\section{Discussion}

The occurrence of mycoplasmas in specimens taken from men before they were given tetracycline could be known only in retrospect. Since mycoplasmas were isolated from only four of 22 men (18 per cent.) it is fortunate that two of them received tetracycline. One other man had a mycoplasma-associated urethritis and also received tetracycline. Mycoplasmas were therefore isolated from a total of five of 23 men (22 per cent). This isolation rate is less than the overall isolation rate seen in the previous study of men in the Antarctic (Holmes and others, 1974), although in the latter study ureaplasmas were isolated from only 28.5 per cent. of men at any one time. Refrigeration failure does not account for a low isolation rate since most of the specimens were taken after this occurred. Nonetheless, it is interesting that organisms could be isolated from twice-thawed specimens in numbers equivalent to those occurring in specimens which had remained frozen.

It is quite clear from the repeated failure to isolate mycoplasmas over a period of about 1 year that the 5-day course of tetracycline completely eliminated them from the genital tract. Ureaplasmas were found again in the genital tract of one subject only after his period of isolation had ended. This means that the reappearance of organisms in the genital tract of antibiotic-treated patients attending a venereal disease clinic is likely to be due to re-infection rather than to multiplication of organisms which have been suppressed but not completely eliminated. A further reason for failure to eliminate ureaplasmas is the administration of an inadequate course of therapy. The recurrence of ureaplasmas in the subject who suffered from NSU and received a 3-day course of tetracycline may fall into this category. The associated reappearance of disease in this patient was an observation similar to that made by Shepard (1974) who used sub-optimal doses of tetracycline. The return of disease concomitant with the reappearance of ureaplasmas might be taken as evidence for the pathogenicity of these organisms. However, one cannot infer this because other tetracycline-sensitive organisms, such as chlamydiae, were not sought. The recurrence or continued presence of ureaplasmas after treatment may also be due to the existence of organisms which are relatively tetracycline-resistant. These have been found in Canada (Ford and Smith, 1974) and in England (Prentice, Taylor-Robinson, and Csonka, 1976). It is noteworthy that all the strains examined in the present study were highly sensitive to the antibiotic in vitro. Weström and Mårdh (1971) were unsuccessful in eliminating ureaplasmas from the genital tract of women by treating them with metacycline. However, Gnarpe and Friberg (1972) were able to clear ureaplasmas from semen for periods of at least 4 to 6 weeks by using doxycycline. Furthermore, Harrison, de Louvois, Blades, and Hurley (1975) successfully eradicated mycoplasmas from cervical and seminal samples for a period of at least 6 months by using doxycycline. The apparent ease of eliminating ureaplasmas from the genital tract is, as indicated previously, in contrast to the difficulty of eliminating them from tissue cultures and from subjects suffering from mycoplasmal respiratory disease. Mazzali and Taylor-Robinson (1971) provided some evidence that ureaplasmas may enter cells in tissue culture, and Furness and Whitescarver (1975) suggest that this may happen with other mycoplasmas. If this is so, it is possible that they are protected from the effects of antibiotics. In $M$. pneumoniae infections, organisms lying close to the cell surface between cilia, and those between cells and within leucocytes and macrophages may be shielded from the effects of antibiotics. It might be argued that ureaplasmas carried apparently as commensals by a healthy person are not so deep-seated and are therefore more susceptible to antibiotics, and that if they were involved in an inflammatory process they might be less easy to eradicate. However, it should be noted that two subjects inoculated intraurethrally with ureaplasmas developed urethritis, including prostatic involvement in one (Taylor-Robinson, Csonka, and Prentice, unpublished). Tetracycline therapy successfully eliminated the organisms because they were not found during the course of the next 9 months.

We thank the members of the British Antarctic Survey (National Environment Research Council) for their 
co-operation, the Survey itself for providing equipment and facilities, and especially D. Frise-Green for supervising the study at Signy Island.

\section{References}

FORD, D. K., and SMITH, J. R. (1974) Brit. f. vener. Dis., 50, 373

Furness, G., and WhitesCarver, J. (1975) Proc. Soc. exp. Biol. (N.Y.), 149, 427

GNARPE, H., and FrIBERG, J. (1972) Amer. f. Obstet. Gynec., 114, 963

HaRrison, R. F., De Louvois, J., Blades, M., and HURLEY, R. (1975) Lancet, 1, 605

Holmes, M. J., FurR, P. M., and TAYLOR-Robinson, D. (1974) f. Hyg. (Camb.), 72, 355
MANCheE, R. J., and TAYLOR-Robinson, D. (1968) F. gen. Microbiol., 50, 465

MAZZALI, R., and TAYLOR-Robinson, D. (1971) f. med. Microbiol., 4, 125

Prentice, M. J., Taylor-Robinson, D., and Csonka, G. W. (1976) Brit. F. vener. Dis., 52, 269

SHEPARD, M. C. (1974) I.N.S.E.R.M., 33, 375

Slotkin, R. I., ClYDE, W. A., and DeNNY, F. W. (1967) Amer. F. Epidemiol., 86, 225

Smith, C. B., Chanock, R. M., Friedewald, W. T., and AlFord, R. H. (1967) Ann. N.Y. Acad. Sci., 143, 471

StANBRIDGE, E. (1971) Bact. Rev., 35, 206

TAYLOR-Robinson, D. (1967) Postgrad. med. f., Suppl. 43, 100

WESTRÖM, L., and MARDH, P.-A. (1971) Acta obstet. gynaec. scand., 50, 25 